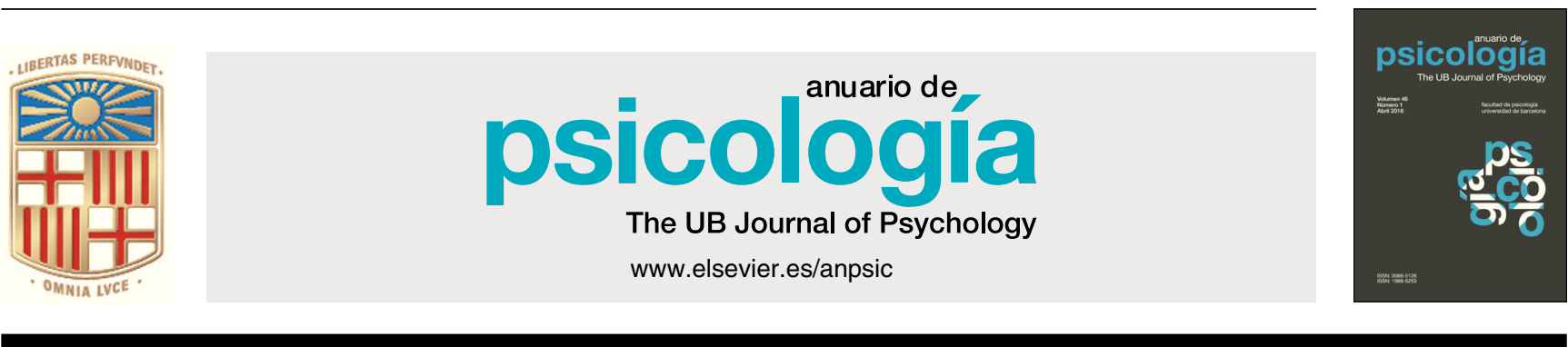

ORIGINAL RESEARCH PAPER

\title{
Referential communication in bilingual Catalan-Spanish children with Specific Language Impairment
}

\author{
Lucía Buil-Legaz, Josep A. Pérez-Castelló, Daniel Adrover-Roig, \\ and Eva Aguilar-Mediavilla*
}

Department of Applied Pedagogy and Educational Psychology, Universitat de les Illes Balears, Palma de Mallorca, Spain

Received 13 January 2016; accepted 24 March 2016

KEYWORDS

Pragmatics;

Visual perspective;

Morphosyntax;

Language difficulties

\section{PALABRAS CLAVE \\ Pragmática; \\ Perspectiva visual; \\ Morfosintaxis; \\ Dificultades \\ del lenguaje}

\begin{abstract}
The aim of the present study was to analyse the quality of messages produced by Catalan-Spanish children with Specific Language Impairment (SLI) during a referential communication task, as compared to age-matched controls at 8 years of age. Children described ten objects arranged in a picture, being some of them ambiguous. Verbal exchanges were transcribed and coded in CHAT format. Results showed that children with SLI produced fewer initial and final correct messages than their age-matched controls and adults used the same type of communicative regulations with both groups. Furthermore, morphosyntactic level assessed at age 7 did not predict the number of correct messages in the referential communication task one year later. We believe that the key difficulty in this task for children with SLI might not be exclusively linguistic and involves the analysis of the communicative context, the ability to extract the relevant information and to consider the adults' perspectives in order to allow them do the task correctly.
\end{abstract}

๔ 2016 Universitat de Barcelona. Published by Elsevier España, S.L.U. All rights reserved.

\section{Comunicación referencial en niños bilinguies del catalán-español con Trastorno Específico del Lenguaje}

Resumen El objetivo del presente trabajo fue analizar la calidad de los mensajes producidos
por niños bilingües con Trastorno Específico del Lenguaje (TEL), hablantes de catalán y español,
en una tarea de comunicación referencial, en comparación con niños controles de la misma
edad a los 8 años de edad. La tarea de los niños consistía en describir la colocación de diversos
objetos de un dibujo, algunos de ellos ambiguos, a un adulto que no veía la imagen. Los inter-
cambios verbales fueron transcritos y codificados en formato CHAT. Los resultados mostraron
que los niños con TEL producían menos mensajes correctos iniciales y finales que sus controles
de edad. Los adultos utilizaron el mismo tipo y cantidad de mensajes para regular la comunica-
ción con ambos grupos. Por otra parte, el nivel morfosintáctico a la edad de 7 años no predijo 
el número correcto de los mensajes en la tarea de comunicación referencial un año después. Creemos que la principal dificultad en esta tarea para los niños con TEL no es exclusivamente lingüística, e implica el análisis del contexto comunicativo, la capacidad de extraer la información relevante y considerar la perspectiva del adulto con el fin de hacer la tarea correctamente.

(c) 2016 Universitat de Barcelona. Publicado por Elsevier España, S.L.U. Todos los derechos reservados.

The aim of this study was to know the adequacy of communicative productions and responses to adult regulations of bilingual Spanish-Catalan children with Specific Language Impairment (SLI) during a referential communication task. Our work is framed within the hypothesis of the limited processing capacity proposed by Leonard (1998). The substantial delay in language acquisition in children with SLI is not related to the factors that usually explain problems in language learning, such as hearing impairment, low IQ, detectable neurological damage, or partner-emotional problems (American Pshychiatric Association, 2013; Leonard, 1998). Besides these common underlying factors, crosslinguistic studies (see Leonard, 2014) have shown that specific characteristics of linguistic profiles of children with SLI vary according to the specificities of a particular language. Among all of the above deficits, pragmatics is one of the least studied components in children with SLI, especially in bilingual populations. Nevertheless, a great international interest has become evident in recent years on this particular topic (Andrés-Roqueta, Clemente-Estevan, \& Flores-Buils, 2012; Osman, Shohdi, \& Aziz, 2011) because learning to communicate correctly is a key factor for appropriate social interaction and normal cognitive development (Yingling, 2004).

In this vein, difficulties in communication can lead to poor social relations and difficulties in both learning and cognition (Pickles, St. Clair, \& Conti-Ramsden, 2013). In order to communicate correctly, linguistic, cognitive and social skills are necessary to be an effective speaker and/or listener. These skills include the ability to analyse the referent to be described in the communicative context, to take into consideration other's perspectives, to adapt language according to feedback, and to interpret non-literal information. Thus, communicative competence is defined as the ability to communicate in a personally effective and socially appropriate manner in a particular context (Trenholm \& Jensen, 1992).

One of the components of the communicative competence involves the referential function that is used in numerous educational settings. Experimental studies in pragmatics have found that the interlocutors' sharing of a physical environment affects referential communication. For instance, keeping the goal of the task can help listeners disambiguate referring expressions in interactive games (Hanna \& Tanenhaus, 2004). This can also affect language production, as when speakers tell stories to interlocutors who either share a picture of the story with the speaker, or rely entirely on the speaker's narrative. In this case, speakers tend to specify atypical objects more often than when these objects are visible to both interlocutors (Lockridge \& Brennan, 2002).

For example, referential abilities might be needed when the child has to describe his/her drawing to the teacher. Following Haslett (1984), the referential communication function refers to the exchange of information related to particular referents. In this sense, the task of the speaker is to transfer information to the listener to allow the identification of a particular referent in a particular context. In order to explore referential communication, experimental settings involve tasks with several referents that must be identified and placed, and only verbal contact is possible given that a blank screen blocks the visual contact between the experimenter and the child. In referential communication tasks, object attributes, such as color and shape, tend to be used redundantly. Specifically, shape and object requests require the listener to visually identify the object in the physical environment as part of the pragmatic process of reference assignment. Therefore, research conducted using object attributes might be relevant for pragmatic models of referential communication (Rubio-Fernández, 2016).

To perform a correct referential communication task, task analysis, role taking and task evaluation are core processes that need to be carried out (Dickson, 1980). In this sense, task analysis demands to understand the communicative setting and to identify a particular referent in order to disentangle what makes it different from the others. Role taking is the ability of the speaker to consider other's perspectives and to adapt the conveyed message considering these perspectives. Final, task evaluation is the ability of the speaker to evaluate the quality of the communicative exchange, which is particularly important when assessing the effectiveness of the final transmitted message. All these skills develop during early childhood and are considered to be acquired by age 7-8 (Rosenberg, 1993).

Most previous studies on referential communication have attempted to explain the possible causes and consequences of ineffective communication in different groups of participants (Matthews, Butcher, Lieven, \& Tomasello, 2012). Furthermore, experimental research in pragmatics has shown that participants are prone to use adjectives in a redundant manner in referential communication tasks (Koolen, Goudbeek, \& Krahmer, 2013).

To date, previous studies on referential communication in children with SLI have shed contradictory results (Bishop \& Adams, 1991; Johnston \& Smith, 1989; Johnston, Smith, \& Box, 1997; Reuterskiöld-Wagner, Nettelbladt, \& Sahlén, 2001). In this vein, some studies have not shown a difference between SLI groups and typically developing children, in terms of communicating relevant information (Johnston et al., 1997; Reuterskiöld-Wagner et al., 2001). However, other works have shown children with SLI to present lower communicative effectiveness as compared to controls when it comes to the selection of relevant information (Bishop \& Adams, 1991; Johnston \& Smith, 1989; Meline \& Brackin, 1987). Despite these contradictory results, studies agree in reporting certain subtle dissimilarities between children with SLI and controls (Bishop \& Adams, 1990; Bishop \& Ad- 
ams, 1991; Johnston et al., 1997; Meline \& Brackin, 1987; Reuterskiöld-Wagner et al., 2001). In this regard, the main difference resides in the strategy used by children with SLI who are more likely to mention the attributes of each object separately rather than to describe the distinctive and common characteristics of a pair of objects (Johnston et al., 1997; Johnston \& Smith, 1989). Focusing on children with SLI speaking Spanish, Andrés-Roqueta and ClementeEstevan (2010) compared a group of participants with conventional SLI to a group of SLI with more pragmatic problems and their respective control group with typical language development between four and seven years of age. The authors showed that groups of children with SLI were able to attribute mental states when the task context was highly structured. However, children with predominant pragmatic SLI performed more poorly than those with conventional SLI when tasks were communicative-oriented and they needed to process non-explicit information from the context. Katsos, Roqueta, Clemente Estevan, \& Cummins (2011) further showed that children with SLI speaking Spanish are not competent with the pragmatic maxim of informativeness, and were thus disproportionately challenged by pragmatic meaning compared to their age-matched peers. Furthermore, the performance of children with SLI was comparable to that of a group of younger language-matched typicallydeveloping children. These difficulties were in keeping with their language difficulties rather than exceeding them.

Thus, descriptive strategies used by children with SLI appear to be simpler and do not seem involve a high levels of cognitive elaboration. Hence, their strategies might be cognitively less demanding than those strategies used by their age-matched peers, which in turn could be due to their difficulty in conveying information. Several authors (Johnston et al., 1997) have interpreted that these differences in the description of objects may indicate the influence of a limited cognitive ability that is reflected during referential communication tasks.

Following this rationale, an account that explains both linguistic and non-linguistic difficulties in children with SLI might be necessary. Given that most of the observed deficits in children with SLI are difficult to constrain to a specific difficulty in the linguistic domain, an account that considers that language problems are due to a more generalized limitation in several cognitive capacities, such as perception, memory, auditory processing, or all of them, might be more suitable as an integrative explanatory account of SLI (see Leonard, 1998; Miller, 2011, for a review).

In this regard, the limited processing capacity hypothesis (Leonard, 1998) argues that children with SLI have difficulties to process rapid, non-salient, brief or complex information because of a limited capacity or/and a general slow processing which would make them feel overload with lower amounts of information as compared to controls. Therefore, these difficulties would affect both the linguistic and nonlinguistic levels. Consequently, children with SLI would show difficulties not only in understanding and in producing words, sentences or narrations, but also in selecting appropriate information, in considering the adults' perspectives or in other processes when facing a complex task or a task that involves high cognitive loads. As we have mentioned, these difficulties affect not only language, but also communication in children with SLI. The clinical significance of these problems in language and communication is worthy of note since they could seriously jeopardise their scholar development and interfere with interpersonal relationships (Pickles et al., 2013).

At this point it is worthy of note that referential communication tasks are linguistically simple (children have only to say one or two words using simple sentences), but cognitively complex (they have to carry out a task analysis, role taking and task evaluation). These conditions might make referential communication tasks a good candidate to evaluate a potential difficulty in pragmatics, communication, and cognition, which is not directly dependent on linguistic abilities and might be a result of a cognitive overloading, as proposed by the limited processing capacity hypothesis (Leonard, 1998). Therefore, the purpose of this study was to evaluate the ability to produce informative messages, and to explore the type of communicative exchange between the child and the adult in a group of bilingual Spanish-Catalan children with SLI, as compared to their age controls using an ecological task of referential communication. Their communicative ability was then related with their performance in the morphosyntactic domain in order to better disentangle language deficits from possible limitations in processing capacity (Leonard, 1998). To do so, we considered the following departing hypotheses:

Hypothesis 1: if children with SLI show a limitation in cognitive processing that makes complex tasks to overload their capacities, their messages would be less appropriate in the referential communication task as compared to their typically developing peers. Specifically, we expect a lower number of correct messages produced by children with SLI.

Hypothesis 2: given that children with SLI might provide with less informative messages, we expect that adults will regulate the communicative exchanges of children with SLI more frequently, thus showing more interventions as compared to those addressed to children in the control group. Thus, we expect that the number of demands of information by adults for further attributes about the referents will be larger when addressed to children with SLI as compared to controls (in both weak and strong regulations).

Hypothesis 3: given that the referential communication task is simple in linguistic terms, we expect that the departing morphosyntactic level of children with SLI at age of seven would not predict performance in the referential communication task one year later. Conversely, if difficulties in the referential communication task were associated to language difficulties in children with SLI, their departing morphosyntactic level be a predictor of performance in the task.

\section{Method}

\section{Participants}

The study group was formed by 15 bilingual Catalan-Spanish children with SLI (ten males), with a mean age of 8.0 years $(S D=0.3)$ at the time of assessment (Table 1 for demographic data). These children were paired with a control group of 15 age-matched typically developing bilingual Catalan-Spanish children (nine males), with a mean age of 8.2 years $(S D=0.2)$. There were neither gender nor age differences between groups (Table 1). 
All children were involved in a longitudinal project conducted in the Balearic Islands, Spain, and fulfilled the established criteria for diagnosing SLI (Leonard, 1998). Schools sent us a brief profile of their pupils at third year of kindergarten (five years of age) showing language problems and without having a history of cognitive, auditory, social or neurological damage. For the initial sample, we also considered other exclusion criteria, such as only presenting with articulatory problems and/or being newly arrived from a non-Catalan speaking community, in order to avoid the sample to include sequential second language learners. Therefore, we pre-selected those bilingual children who presented with only language problems and no other potential associated difficulties.

Then, we assessed their general language profiles (Form: phonology and morphosyntax; Content: lexicon, and Use: pragmatics) using the PLON-R: Prueba del Lenguaje Oral de Navarra Revisada 'PLON-R: Navarra Oral Language Test Revised' (Aguinaga, Armentia, Fraile, Olangua, \& Uriz, 2004). The linguistic profile according to PLON-R was form and content (phonological-syntactic and lexical-syntactic) in children with SLI, but not pragmatic (see Table 1). The equivalent departing pragmatic capacities between both groups might help to better evaluate their potential under- lying difficulties in performing the experimental task, given that there was not an apparent selective deficit in pragmatics among children with SLI. Participants who had moved to another country or did not fulfil standard criteria for SLI were not considered for the follow-up of in longitudinal study.

Non-verbal Intelligence Quotient (IQ) was measured by means of the Wechsler Preschool and Primary Scale of Intelligence (Wechsler \& de la Cruz, 2001). Neurological, social and emotional data were obtained from speech therapists at school. We also requested their records related to audition to the Balearic Ministry of Health. This institution conducts an Otoacoustic Emissions (OAE) analysis to all children in Majorca and an audiometric test to those children that fail the OAE at the age of six. Thus, the study group was comprised of children born in Majorca who showed language difficulties, as measured by PLON-R, with an IQ higher than 85 , and no evidence of auditory, social, emotional or neurological problems. Children in the SLI group obtained significantly lower scores than controls in terms of the total score in the PLON-R and did not differ with children in the control group in terms of non-verbal IQ (Table 1).

The control group was comprised by children without language problems going to the same classrooms and having the

Table 1 Demographic data

\begin{tabular}{|c|c|c|c|}
\hline & SLI & Age controls & Statistic and significance \\
\hline$n$ & 15 & 15 & - \\
\hline Gender & & & $x^{2}=0.14 ; p=.50$ \\
\hline Male & 10 & 9 & \\
\hline Female & 5 & 6 & \\
\hline \multicolumn{3}{|l|}{ Instruction language } & - \\
\hline Catalan & 15 & 15 & \\
\hline Family language & & & $x^{2}=1.29 ; p=.22$ \\
\hline Catalan & 4 & 7 & \\
\hline Spanish & 11 & 8 & \\
\hline Parental involvement in education ${ }^{a}$ & $M d n=3$ & $M d n=4$ & $U=86 ; p=.26$ \\
\hline Socioeconomic status ${ }^{b}$ & & & $x^{2}=0.22 ; p=.90$ \\
\hline Low & 1 & 2 & \\
\hline Medium & 9 & 10 & \\
\hline High & 1 & 1 & \\
\hline \multicolumn{4}{|l|}{ Time 1} \\
\hline Age & $M=5 ; 8 ; S D=0.3$ & $M=5 ; 9 ; S D=0.2$ & $U=77 ; p=.15$ \\
\hline Language percentile (PLON-R) & $M=25.3 ; S D=10.9$ & $M=57.2 ; S D=21.0$ & $U=15 ; p=p<.001$ \\
\hline PLON-Form & $M=2.31 ; S D=.87$ & $M=3.27 ; S D=.88$ & $U=18.3 ; p<.005$ \\
\hline PLON-Content & $M=3.31 ; S D=1.40$ & $M=4.82 ; S D=.96$ & $U=16.5 ; p<.001$ \\
\hline PLON-Use & $M=1.94 ; S D=.44$ & $M=2.18 ; S D=.66$ & $U=138.5 ; p=.27$ \\
\hline Nonverbal-IQ (WPPSI) & $M=101.5 ; S D=11.3$ & $M=110.3 ; S D=12.4$ & $U=54 ; p=.12$ \\
\hline \multicolumn{4}{|l|}{ Time 2} \\
\hline Age & $M=6 ; 10 ; S D=0.3$ & $M=6 ; 11 ; S D=0.2$ & $U=77 ; p=.15$ \\
\hline Language percentile (TSA-Catalan) & $M=17.0 ; S D=16.0$ & $M=65.0 ; S D=21.8$ & $U=5.5 ; p<.001$ \\
\hline
\end{tabular}

M, mean; SD, standard deviation.

a Likert scale with 5 items from little to a lot of involvement in children's education.

${ }^{\mathrm{b}}$ There were six missing values. 
same age and dominant language as children with SLI. Thus, each participant with SLI was initially paired with a control child in terms of schooling, age and dominant language. Language, intelligence, auditory, social, emotional, and neurological variables were also recorded for the control group. Their language of instruction at school was Catalan (see language of participants and language assessment section, for a more detailed explanation). All participants were followed over six years until they reached the age of 12 years, but the present study only includes dependent measures between ages of seven and eight. The referential communication task was administered at age of eight. One year earlier, at the age of 7 years, the TSA: el desarrollo morfosintáctico del niño 'Child Morphosyntactic Development' (Aguado, 1989) was administered in order to reconfirm the language difficulties and to obtain a morphosyntactic score. Children in the SLI group obtained significantly lower scores than controls in terms of the total score in the TSA (Table 1).

\section{Language of participants and language of assessment}

Participants in the present study were all simultaneous proficient Spanish-Catalan bilinguals (Table 1). With regard to the family language, seven children in the control group mainly spoke Catalan at home and eight spoke Spanish. In the group of children with SLI, four children mainly used Catalan at home, and 11 used Spanish. There were no differences in terms of language use at home (Table 1).

With respect to the language of assessment during the referential communication task, we allowed children to choose the language of response, and the interviewer adapted his/her language according to the children's preferences. In so doing, seven children from the control group answered in Catalan, six answered in Spanish and two responded in both languages. In the SLI group, two children answered in Catalan, 11 in Spanish and two did so in both languages. There were no differences in terms of language choice for the referential communication task (Table 1).

Finally, the TSA (Aguado, 1989) was administered in Catalan (Table 1). As stated above, morphosyntactic structures of Catalan and Spanish are very similar, and some children answered by using both languages. Code mixing is frequent in bilingual communities and thus, we considered correct answers provided in Catalan and also provided in Spanish when the morphosyntactic structure used was appropriate. Mixing languages while preserving the correct syntactic structure was also considered correct.

\section{Tasks and procedure}

The referential communication task used was based on the system created by Krauss and Glucksberg (1969) were two subjects sit at a table facing each other separated by an opaque screen, which prevents visual contact between them. In this case, the child is the speaker and the adult has two roles: the role of listener and the role of regulating the communicative behaviour of the child, re-establishing communicative interaction when necessary. The child was presented with a picture $(297 \mathrm{~cm} \times 490 \mathrm{~cm})$ of a room with different furniture, as well as ten objects, such as an airplane, a car and a little book, among others, which were located in different places around the room (spatial description task, see Appendix A). Four of the objects in the picture were unique and non-ambiguous, and six were ambiguous (i.e. the same objects, yet in different colours or sizes, such as a big book or a little book). The adult had the same picture display, but the objects were not placed on the corresponding site. The task of the child (the speaker) was to describe the arrangement of the objects as placed in the picture and the adult (the listener) had to place each object in his/her picture, attempting to reconstruct their arrangement based on the speaker's instructions. The aim of the task was to produce two identical pictures at the end. For this task, the following instructions were given:

"Now I have given you a sheet with many objects in the room. You must explain to me exactly where those things are. I have a picture of the same room, yet with no objects, and I will have to paste them in. When you are ready, we can start."

Thus, the child had to tell where to place the objects in the picture, as correctly as possible, in order to put them into the right places. When the child produced an ambiguous or an incorrect message, the adult had to regulate the behaviour of the child so that he/she could improve the informative content of the message as many times as he/she considered necessary in order to reach a correct description. For this purpose, the adult could use strong regulations, to request further information, or weak regulations, in order to spur the child to expand on the information, yet without directly asking the child to specify the object or the location of the referent. This specific task is an adaptation of "organization of a room" by Boada and Forns (2004). A group of trained undergraduate Spanish-Catalan bilingual students administered all tasks at the children's schools. All did not know whether the participants belonged to the study group or to the control group. Every examiner assessed a child with SLI and his/her paired control, in order to minimise differences between examiners.

A photograph displayed the two sheets at the end of each session, to record the exact position of each object. Then, language samples were transcribed and coded in CHAT format (MacWhinney, 2000). Codes classify messages by their type (initial, final or reformulated), by their accuracy (correct, erroneous, ambiguous or omitted) and by the object (referent) specification (attributes) and its location (spatial elements). The coding was checked by two independent reviewers and levels of conformity were established in order to ensure an optimal level of reliability (see Reliability section). The specific codes of the referential communication task, the types of errors and adult regulations can be consulted in Appendix B.

\section{Reliability}

Before an agreement was reached by the two external evaluators, two reviewers assigned codes to eight transcriptions randomly selected, four for each group of children, and used the relay software from CHILDES project (MacWhinney, 2000) to determine the levels of concordance between them. The level of reliability between the two coders was 0.83 . 


\section{Results}

\section{Independent sample comparisons}

Independent sample comparisons were carried out between the group of children with SLI and the control group using non-parametric tests, because each group included less than 30 participants. Because of the high number of a priori planned comparisons, the Bonferroni correction was applied separately for each analysis, thus allowing us to reduce Type I error. This procedure resulted in a cut-off criterion for significance at .05, .03, .02, .02 and .03 for measures of message quality, type of correct messages, inappropriate elements, type of inappropriate messages, and communicative exchange. Effect sizes were calculated with $r$ and we have interpreted these results using Cohen's (1988) categories: small effect size $r=.1$, medium $r=.3$, and large $r=.5$.

First, we show an independent sample analysis between groups for the total number of messages produced (Table 2 ) in order to show that total messages were equivalent between both groups and thus comparisons were not biased by different production rates. The messages were classified as initial, final and reformulations. As it can be seen in Table 2, there were no significant differences in the initial number, final number and the number of reformulations between children with SLI and age-matched controls at age of eight.

Regarding results of the message quality in terms of correct messages produced by the child to the listener (see Figure 1), we found significant differences between children with SLI and controls. Specifically, the control group produced significantly more correct messages than children with SLI, with a medium-to-large effect size $(U=44.00$, $p=.01, r=.49$ ). Considering the type of messages produced, this statistically significant difference was true for both initial and final messages, with medium-to-large effect sizes (Table 2).

With respect to the type of inappropriate description of the referents (object identification, object specification attributes- and object location), results showed no significant differences in any of the measured variables (Table $3)$. Finally, with respect to the type of inappropriate messages (Table 3 ), none of the measures (ambiguous, omitted or erroneous message) showed differences between both groups.

Our results support hypothesis 1 , as we found a lower number of correct messages conveyed by children with SLI during the referential communication task. This might be seen as a communicative ineffectiveness, which can be observed both at the initial message and also at the final message, after the regulations had been provided. Thus, children with SLI could not take advantage (in form of reformulations) from adult exchanges/demands (regulations) in order to produce a correct final message. In addition, any of the inappropriate type of elements in the messageobject, object specification or location-, nor any type of inappropriate message-ambiguous, omitted or erroneous message-seemed to characterize the lower number of correct responses provided by children with SLI. Therefore, the lower number of correct messages produced by children with SLI, even with an equivalent baseline number of delivered messages, was explained by the sum of the rates of the different inappropriate elements rather than a dis-

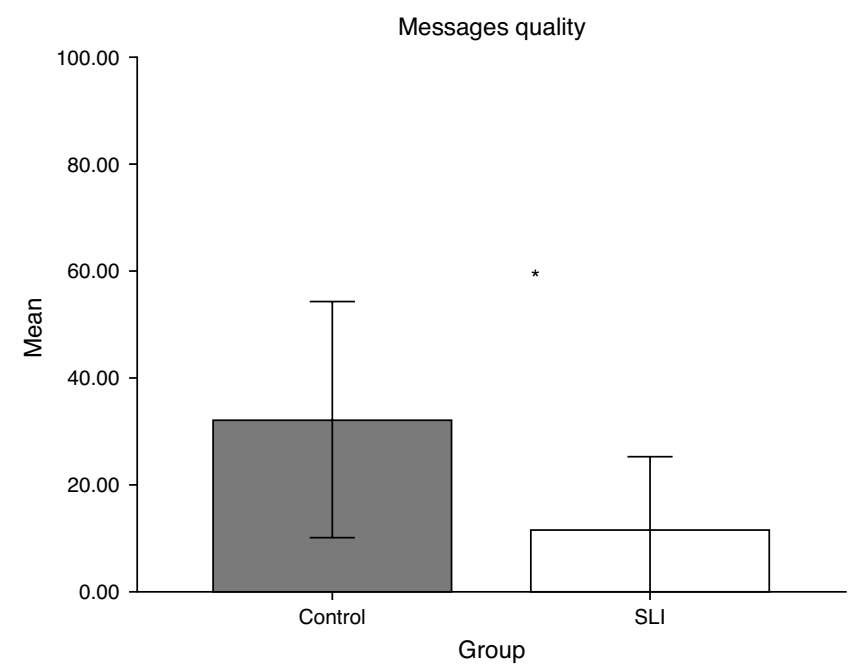

Figure 1 Median and standard deviation of message quality (total number of initial and final correct messages) in children with SLI and age-matched controls in the referential communication task.

Table 2 Production baseline and type of correct messages in the referential communication task in children with SLI and age controls

\begin{tabular}{|c|c|c|c|c|c|c|c|}
\hline \multirow[t]{2}{*}{ Production baseline* } & \multicolumn{2}{|c|}{ SLI } & \multicolumn{2}{|c|}{ Age controls } & \multirow[t]{2}{*}{$U$} & \multirow[t]{2}{*}{$p^{*}$} & \multirow[t]{2}{*}{$r$} \\
\hline & $M$ & $S D$ & $M$ & $S D$ & & & \\
\hline Initial sentences & 10.06 & 0.59 & 10.20 & 0.77 & 104.5 & .74 & .09 \\
\hline Final sentences & 4.53 & 2.79 & 4.80 & 2.45 & 108.0 & .87 & .05 \\
\hline Reformulations & 3.46 & 3.87 & 3.46 & 3.09 & 104.5 & .74 & .00 \\
\hline \multicolumn{8}{|c|}{ Type of correct messages** } \\
\hline Initial & 6.62 & 10.22 & 19.17 & 16.49 & 57.50 & .02 & .41 \\
\hline Final & 4.96 & 5.56 & 12.92 & 8.47 & 55.50 & .02 & .48 \\
\hline
\end{tabular}

M, mean; SD, standard deviation; U, Mann-Whitney U; r, effect size.

A threshold level of significance $p<.02^{*}$ and $p<.03^{* *}$ was considered after Bonferroni correction. 
Table 3 Mean and standard deviation of inappropriate elements of the object and inappropriate messages in the referential communication task

\begin{tabular}{|c|c|c|c|c|c|c|c|}
\hline \multirow[t]{2}{*}{ Inappropriate elements } & \multicolumn{2}{|c|}{ SLI } & \multicolumn{2}{|c|}{ Age controls } & \multirow[t]{2}{*}{$U$} & \multirow[t]{2}{*}{$p^{*}$} & \multirow[t]{2}{*}{$r$} \\
\hline & $M$ & $S D$ & $M$ & $S D$ & & & \\
\hline Object & 1.66 & 1.91 & 1.73 & 1.48 & 106.50 & .80 & .02 \\
\hline Object specification & 3.86 & 3.20 & 3.20 & 4.12 & 137.00 & .32 & .08 \\
\hline Location & 14.46 & 6.25 & 10.06 & 6.69 & 150.00 & .12 & .32 \\
\hline \multicolumn{8}{|c|}{ Type of inappropriate messages } \\
\hline Ambiguous & 12.93 & 5.82 & 9.00 & 5.76 & 152.0 & .10 & .32 \\
\hline Omitted & 4.20 & 3.05 & 3.73 & 4.63 & 139.5 & .26 & .05 \\
\hline Erroneous & 1.87 & 2.53 & 1.47 & 1.76 & 119.0 & .80 & .09 \\
\hline
\end{tabular}

M, mean; SD, standard deviation; U, Mann-Whitney U; $r$, effect size.

${ }^{*} A$ threshold level of significance $p<.02$ was considered after Bonferroni correction.

ruption in a particular information provided (either regarding the referent or regarding the type of inappropriate message).

Following hypothesis 2 , we expected a higher number of adult regulations (weak and strong) addressed to children with SLI, and results (see Table 4) did not show significant differences in any of the variables analysed. Thus, results reject our hypothesis 2 .

\section{Regression analyses}

In order to test hypothesis 3, we conducted three standard regression analyses with morphosyntactic score (TSA) at the age of seven as the predictor variable for the number of correct messages in the referential communication task at the age of eight. The first regression analysis was conducted with the whole sample of participants; the second included only children with SLI, and the third was comprised by children in the control group. Results with all participants showed that the morphosyntactic score at the age of seven was not a significant predictor of the number of correct messages in the referential communication task evaluated one year later $\left(R^{2}=.13, \Delta R^{2}=.09, F(1,28)=4.03, B=.24, \beta=.35\right.$, $p=.06)$. The regression model was not statistically significant and explained a low percentage of the variance (9\%) observed in the number of correct messages produced by children. The results of the regression analysis including with the SLI group and the control separately group showed even lower values as compared to the first regression model
(SLI group: $R^{2}=.01, \Delta R^{2}=-.06, F(1,13)=0.15, B=.09, \beta=.11$, $p=.70$; control group: $R^{2}=.03, \Delta R^{2}=-.05, F(1,13)=0.36, B=-$ $.17, \beta=-.16, p=.56)$. Following hypothesis 3 , morphosyntactic scores did not play a significant role in the referential communication task and thus other abilities, perhaps outside the linguistic domain, might be involved referential communication.

\section{Discussion}

The aim of this study was to describe and to compare the performance in a referential communication task between Spanish-Catalan children with SLI and their age-matched controls. We show that Spanish-Catalan bilingual children with SLI are less effective in this referential communication task as compared to typically developing children as revealed by their lower number of correct responses. Thus, children with SLI might display a low effectiveness in delivering information to listeners about referents because they produce fewer correct messages, being these either ambiguous, incorrect or with omitted information.

Previous studies have found similar results; for instance, Bishop and Adams (1991) found that children with SLI usually display a lower performance in relation to their control peers in terms of the adequacy of the information delivered to the listeners. We observe the same results in our study, where children in the SLI group produce fewer correct messages, both at the initial and at the final stage of the communication process. Therefore, children with SLI seem to

Table 4 Communicative exchange between adults and children during the referential communication task

\begin{tabular}{|c|c|c|c|c|c|c|c|}
\hline \multirow[t]{2}{*}{ Communicative exchange } & \multicolumn{2}{|c|}{ SLI } & \multicolumn{2}{|c|}{ Age controls } & \multirow[t]{2}{*}{$U$} & \multirow[t]{2}{*}{$p^{*}$} & \multirow[t]{2}{*}{$r$} \\
\hline & $M$ & $S D$ & $M$ & $S D$ & & & \\
\hline \multicolumn{8}{|l|}{ Adult } \\
\hline Keep conversation & 9.00 & 6.29 & 13.47 & 6.17 & 68.5 & .06 & .33 \\
\hline Regulations (S+W) & 10.66 & 7.76 & 9.13 & 6.33 & 126.5 & .56 & .10 \\
\hline
\end{tabular}

M, mean; SD, standard deviation; U, Mann-Whitney U; r, effect size; S, strong regulations; W, weak regulations.

*A threshold level of significance $p<.03$ was considered after Bonferroni correction. 
beneficiate less from their interaction with adults, being this independent of the number of messages conveyed, given that the production baseline regarding initial and final sentences, and the number of reformulations was equivalent between both groups. Results from a different referential task from Meline and Brackin (1987) also showed that children with SLI have difficulties in detecting the causes of a conversational communication gap. In their task, the speaker made a claim to the listener but formulated a message too general to be understood, and participants had to decide whether the communicative failure was due to the speaker or to the listener. Children with SLI were listenerblamers, whereas age controls were speaker-blamers. These results suggest that children with SLI have problems assessing the effectiveness of the communicative exchange. This could also be the case in the present work, since we believe that children with SLI were not fully able to assess if their initial messages were sufficiently informative and to become aware of it after feedback. As a result, the final message delivered is less 'efficient' than that of children in the control group, in terms of the amount of information conveyed.

Nevertheless, neither the type of elements in the message (object, object specification or object location), nor the type of inappropriate message (ambiguous, omitted or erroneous), showed significant effects between both groups of children. Therefore, the fewer number of correct messages in children with SLI as compared with typically developing children is due to a low performance specifying both the elements, their attributes and their locations, and does not show a specific pattern of errors.

With respect the communicative exchange, adults' interventions carried out in order to maintain the conversation and to regulate child messages, contrary to our hypothesis, are as frequent in children with SLI as in the control group. Besides, the number of reformulations required to reach the final message is also not significant between both groups. Given that adults (listeners) are blind in terms of to which group belonged each child, we believe they do not produce a larger number of regulations for children with SLI because they detect the child's difficulty to produce and reformulate the message and aim to prevent anxiety in children with SLI. Another possibility is that adults stop the regulations because the child becomes unresponsive, and/or returns a similar ambiguous or incorrect message repeatedly. Independently of these tentative explanations, adults do not continue with the communicative exchange despite the final message is not correct. Hence, it might be that the experimenters are concerned with keeping the communication open in order to reach a similar production baseline than regulating the appropriateness of the communicative behaviour. All these factors, together with children's inherent difficulties in adapting their messages to the listener might lead them to not benefit enough from adults' interactions resulting in fewer correct utterances.

Another of the main aim of the present study is to explore the morphosyntactic level at the age of seven as a predictor of performance in the referential communication task one year later. We show that performance in a morphosyntactic task does not predict how well children carry out the referential communication task one year later. Thus, both pro- cesses might not be strongly related and could not be mutually dependent. In this vein, a recent study that used a narration task also found that children with SLI showed not only a fragile linguistic structure, but also difficulties in the pragmatic aspects of storytelling, related to referencing, event content, mental state expressions and inferring (Mäkinen, Loukusa, Laukkanen, Leinonen, \& Kunnari, 2014). However, it is worthy of note that the small sample size in our research work make us take the present results with caution.

We propose that the lower number of correct messages delivered by children with SLI might be related to their difficulties to process information (Johnston et al., 1997; Leonard, 1998). In particular, children with SLI, due to the cognitive complexity of the task, might not be able to analyse which are the listener's needs that make it possible to differentiate one referent from the others, and might find it difficult to provide the adequate indications that allow placing the object in the right place. In other words, the speaker fails at adopting the perspective of others, which is a basic aspect of theory of mind (Farrant, Fletcher, \& Maybery, 2006) and a central component of pragmatics.

A similar account was provided by Johnston et al. (1997) who showed that children with SLI had a particular difficulty in performing certain tasks within the referential communication paradigm. When it came to producing messages, children with SLI did not appear to have difficulties in terms of language per se, but rather displayed difficulty in structuring their messages, in specifying the relevant characteristics to transmit an effective message, in grasping ambiguity, in detecting the importance of clarifying the message and in viewing the situation from the perspective of their interlocutors.

\section{Conclusions}

The present study shows that children with SLI display a lower communicative efficiency in terms of the number of correct messages delivered, which is independent of both their production baseline, the number of adult regulations and their departing morphosyntactic level. Typically developing eight-year-old children produce correct messages; they can also adapt their utterances to listeners and are capable of evaluating the quality of their communication in referential communication tasks (Rosenberg, 1993). In this sense, an interesting line of future research would be to determine whether communicative quality could be improved through specific training. Such training would involve the improvement of children's capacity to offer informative messages, to evaluate several situations from different perspectives and to assess the quality of the information they deliver.

\section{Acknowledgments}

This work was supported by the Spanish government and the ERDF: European Regional Development Fund [SEJ200612616]. Special thanks to all the children who participated, to their families, and to their schools. 


\section{Appendix A Picture used in the referential communication task}

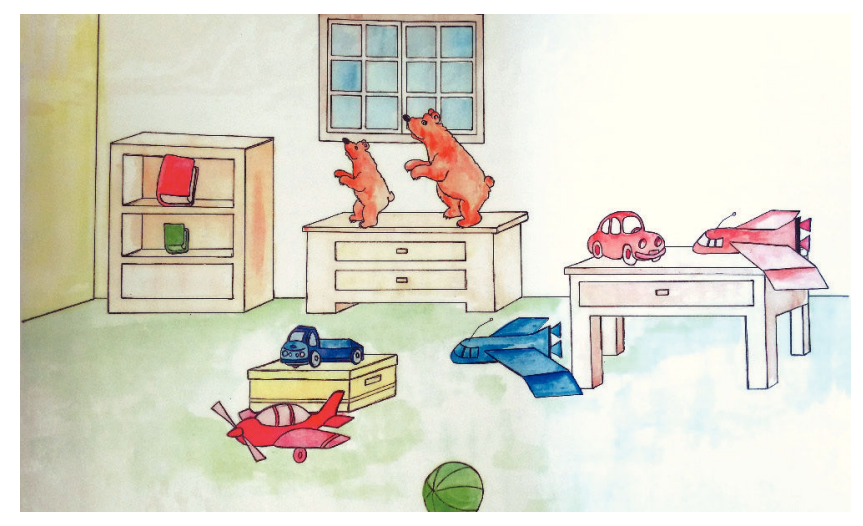

\section{Appendix B Codes of the referential communication task}

Table B.1 Message quality

\begin{tabular}{llll}
\hline Message type & Object & $\begin{array}{l}\text { Object } \\
\text { specification }\end{array}$ & $\begin{array}{l}\text { Object } \\
\text { location }\end{array}$ \\
\hline Initial message I & Correct C & Correct C & Correct C \\
Final message F & Erroneous E & Erroneous E & Erroneous E \\
Reformulation R & Omitted O & Omitted O & Omitted O \\
& Ambiguous A & Ambiguous A & Ambiguous A \\
\hline
\end{tabular}

Table B.2 Communicative exchange

\begin{tabular}{llll}
\hline $\begin{array}{l}\text { Type of } \\
\text { exchange }\end{array}$ & $\begin{array}{l}\text { Keeping } \\
\text { conversation }\end{array}$ & $\begin{array}{l}\text { Weak } \\
\text { regulation }\end{array}$ & $\begin{array}{l}\text { Strong } \\
\text { regulation }\end{array}$ \\
\hline Adult & {$[+\mathrm{AM}]$} & {$[+\mathrm{AD}]$} & {$[+\mathrm{AT}]$} \\
\hline
\end{tabular}

\section{Example of messages}

${ }^{*} \mathrm{CHI}$ : el llibre petit devora sa taula [: 'the little book near the table']. [+ ICCA]

*EXA: devora sa taula, on [: 'near the table, but where']? [+AT]

*CHI: a devora es moble de devora de sa finestra [: 'beside the dresser next to the window']. [+ RCCA]

*EXA: es moble de devall sa finestra o sa taula [: 'the dresser under the window or the table']? [+ AT]

*CHI: es moble [: 'the dresser']. [+ RCCA]

*EXA: i a es moble, a on [: 'and where in the dresser']? [+ AT]

*CHI: at segon prestatge [: 'at the second shelf']. [+ FCCC]

*EXA: al segon prestatge, be [: 'at the second shelf, ok']. [+ AM]

\section{Type of messages}

- Initial: The first message formulated about an object.

- Final: The last message formulated about an object.

- Reformulated: A message uttered between the initial and the final messages, which aims to provide new data about the referent. This message is usually produced because of adult intervention.

\section{Object}

- Correct $(C)$ : the object is appropriately identified and named correctly when formulating the message.

${ }^{*} \mathrm{CHI}$ : the little book at the second shelf of the bookcase. [+ ICCC]

- Erroneous (E): It identifies an erroneous item.

${ }^{*} \mathrm{CHI}$ : the little car at the second shelf of the bookcase. [+ IECC]

- Ambiguous (A): The explanation of the object does not clarify the referent.

${ }^{*} \mathrm{CHI}$ : The little thing at the second shelf of the bookcase. [+ IACC]

- Omitted (O): the referent is not identified.

${ }^{*} \mathrm{CHI}$ : the little at the second shelf of the bookcase. $[+\mathrm{IOCC}]$

\section{Object specification}

- Correct $(C)$ : The attributes required to identify the referent (colour, shape, size) are mentioned.

${ }^{*} \mathrm{CHI}$ : the little book at the second shelf of the bookcase. [+ ICCC]

- Erroneous $(E)$ : The attributes required to identify the referent are incorrectly mentioned.

${ }^{*} \mathrm{CHI}$ : the big book at the second shelf of the bookcase. [+ ICEC]

- Ambiguous $(\mathrm{A})$ : The distinguishing attributes of the referent are described but not specified.

${ }^{*} \mathrm{CHI}$ : the other book at the second shelf of the bookcase. [+ICAC]

- Omitted (O): The distinguishing attributes of the referent are not specified.

${ }^{*} \mathrm{CHI}$ : the book at the second shelf of the bookcase. [+ICOC]

\section{Object location}

- Correct $(\mathrm{C})$ : It explains the correct location of the referent.

${ }^{*} \mathrm{CHI}$ : the little book at the second shelf of the bookcase. [+ ICCC]

- Erroneous (E): It cities a place that does not correspond to the correct site where the referent should be placed.

${ }^{*} \mathrm{CHI}$ : the little book at the first shelf of the bookcase. [+ ICCE]

- Ambiguous (A): The details provided for the correct placement of the referent are doubtful or unclear.

${ }^{*} \mathrm{CHI}$ : the little book at the bookcase. [+ ICCA]

- Omitted (O): The location of the referent is not specified. ${ }^{*} \mathrm{CHI}$ : the little book. [+ ICCO]

\section{Kind of communicative exchange}

- Keeping conversation: Used to keep the communication channel open or keep the activity going. They do not provide information about the referent.

${ }^{*} \mathrm{CHI}$ : the little book at the first shelf of the bookcase. [+ ICCO]

*EXA: ok. [+ AM]

- Weak regulation: Indirectly regulates the behaviour of another person to obtain more information about the referent. 
${ }^{*} \mathrm{CHI}$ : in a bookcase, under a ball. [+ RCCA]

*EXA: there isn't a ball. [+ AD]

- Strong regulation: Directly regulates the behaviour of another person by directly requesting new information about the referent.

${ }^{*} \mathrm{CHI}$ : on the table. [+ RCCA]

*EXA: where on the table? [+ AT]

\section{References}

Aguado, G. (1989). TSA: el desarrollo morfosintáctico del niño. Madrid: CEPE.

Aguinaga, G., Armentia, M., Fraile, A., Olangua, P., \& Uriz, N. (2004). Prueba de lenguaje oral de Navarra-Revisada (PLON-R). Madrid: TEA.

American Pshychiatric Association (2013). DSM-5: Diagnostic and statistical manual of mental disorders. Washington, DC: American Psychiatric Association.

Andrés-Roqueta, C. A, \& Clemente-Estevan, R.A. (2010). Pragmatic difficulties in children with specific language impairment. The role of mentalistic tasks. Psicothema, 22(4), 677-683.

Andrés-Roqueta, C. A., Clemente-Estevan, R. A., \& Flores-Buils, R. (2012). Social cognition and pragmatic competence. The case of children with specific language impairment. International Journal of Psychological Research, 5(1), 59-69.

Bishop, D. V. M., \& Adams, C. (1990). A prospective study of the relationship between specific language impairment, phonological disorders and reading retardation. Journal of Child Psychology and Psychiatry, 31(7), 1027-1050.

Bishop, D. V. M., \& Adams, C. (1991). What do referential communication tasks measure? A study of children with specific language impairment. Applied Psycholinguistics, 12(02), 199-215.

Boada, H., \& Forns, M. (2004). The cognitive complexity of the referent and self-regulation in children's messages. Journal of Psycholinguistic Research, 33(3), 237-261.

Cohen, J. (1988). Statistical power analysis for the behavioral sciences. New Jersey: LEA.

Dickson, W. P. (1980). Referential communication performance. Evaluation in Education, 4(C), 84-85.

Farrant, B. M., Fletcher, J., \& Maybery, M. T. (2006). Specific language impairment, theory of mind, and visual perspective taking: evidence for simulation theory and the developmental role of language. Child Development, 77(6), 1842-53.

Hanna, J. E., \& Tanenhaus, M. K. (2004). Pragmatic effects on reference resolution in a collaborative task: evidence from eye movements. Cognitive Science, 28, 105-115.

Haslett, B. (1984). Communication development in children. In R. Bostrom (Ed.), Communication yearbook, 8 (pp. 198-266). Beverly Hills, CA: Sage.

Johnston, J. R., \& Smith, L. B. (1989). Dimensional thinking in language impaired children. Journal of Speech and Hearing Research, 32(1), 33-38.

Johnston, J. R., Smith, L. B., \& Box, P. (1997). Cognition and communication: referential strategies used by preschoolers with specific language impairment. Journal of Speech, Language, and Hearing Research, 40(5), 964-974.
Katsos, N., Roqueta, C. A., Clemente Estevan, R. A. \& Cummins, C. (2011) Are children with Specific Language Impairment competent with the pragmatics and logic of quantification? Cognition, $119,43-57$

Koolen, R., Goudbeek, M., \& Krahmer, E. (2013). The effect of scene variation on the redundant use of color indefinite reference. Cognitive Science, 37, 395-411.

Krauss, R. M., \& Glucksberg, S. (1969). The development of communication competence as a function of age. Child Development, 40(1), 255-266.

Leonard, L. (1998). Children with specific language impairment. Massachusetts: MIT Press (MA).

Leonard, L. (2014). Specific language impairment across languages. Child Development Perspectives, 8(1), 1-5.

Lockridge, C. B., \& Brennan, S. E. (2002). Addressees' needs influence speakers' early syntactic choices. Psychonomic Bulletin Reviews, 9, 550-557.

MacWhinney, B. (2000). The CHILDES project: Tools for analyzing talk. Hillsdale, NJ: Lawrence Erlbaum Associates.

Mäkinen, L., Loukusa, S., Laukkanen, P., Leinonen, E., \& Kunnari, S. (2014). Linguistic and pragmatic aspects of narration in Finnish typically developing children and children with specific language impairment. Clinical Linguistics \& Phonetics, 28(6), 413-427.

Matthews, D., Butcher, J., Lieven, E., \& Tomasello, M. (2012). Two and four-year-olds learn to adapt referring expressions to context: Effects of distracters and feedback on referential communication. Topics in Cognitive Science, 4(2), 184-210.

Meline, T. J., \& Brackin, S. R. (1987). Language-impaired children's awareness of inadequate messages. The Journal of Speech and Hearing Disorders, 52(3), 263-270.

Miller, C. A. (2011). Auditory processing theories of language disorders: Past, present, and future. Language, Speech, and Hearing Services in Schools, 42(3), 309-319.

Osman, D. M., Shohdi, S., \& Aziz, A. A. (2011). Pragmatic difficulties in children with specific language impairment. International Journal of Pediatric Otorhinolaryngology, 75(2), 171-176.

Pickles, A., St. Clair, M. C., \& Conti-Ramsden, G. (2013). Communication and social deficits in relatives of individuals with SLI and relatives of individuals with ASD. Journal of Autism and Developmental Disorders, 43(1), 156-167.

Reuterskiöld-Wagner, C., Nettelbladt, U., \& Sahlén, B. (2001). Giving the crucial information: performance on a referential communication task in Swedish children with language impairment. International Journal of Language \& Communication Disorders, 36(4), 433-445.

Rosenberg, S. (1993). Development of linguistic communication. In S. Rosenberg \& L. Abbeduto (Eds.), Language and communication in mental retardation: Development, processes, and intervention. Topics in applied psycholinguistics Associates, Inc. (pp. 129-162). Hillsdale, NJ. England: Lawrence Erlbaum Associates.

Rubio-Fernández, P. (2016). How redundant are redundant color adjectives? An efficiency-based analysis of color overspecification. Frontiers in Psychology, 7:153.

Trenholm, S., \& Jensen, A. (1992). Interpersonal communication. Oxford: Oxford University Press.

Wechsler, D., \& de la Cruz, M. V. (2001). Escala de inteligencia de Wechsler para preescolar y primaria: WPPSI. Madrid: TEA.

Yingling, J. (2004). A lifetime of communication. Mahwah, NJ: Lawrence Erlbaum Associates. 